\title{
ELECTROCARDIOGRAPHIC CHANGES IN PATIENTS OF ACUTE ISCHEMIC STROKE IN RURAL TERTIARY CARE HOSPITAL
}

\section{Dr.S. Sathish Kumar*}

\section{Dr. Y.s. Kanni}

\section{$3^{\text {rd }}$ Year Resident, Kamineni Institute Of Medical Sciences, Narketpally,} Nalgonda, Telangana. * Corresponding Author

Professor, Dept Of General Medicine, Kamineni Institute Of Medical Sciences, Narketpally, Nalgonda, Telangana.

ABSTRACT BACKGROUND:Stroke is the major cause of mortality and morbidity worldwide. In cerebrovascular accidents ischemic strokes are more common than hemorrhagic strokes. Electrocardiographic (ECG) changes are common in acute ischemic strokes. These ECG changes mimics myocardial ischemia. The main aim of this study is to study electrocardiographic changes that occur in acute ischemic stroke.

METHODS: Seventy patients with acute ischemic stroke were included in the study. For all patients CT/MRI brain was done to confirm the diagnosis. A 12 lead ECG was taken for all patients at the time of admission.

RESULTS: Out of seventy patients 44 patients were males (62.9\%) and 26 (37.1\%) patients were females. The mean age in our study was $60.35 \pm 10.21$ years. $91.42 \%$ of patients have ECG changes and $8.57 \%$ have normal ECG. The most common ECG change observed is T wave inversion (38.57\%) followed by ST segment changes $(25.71 \%)$. some patients have more than one ECG change.

CONCLUSION: This study shows the importance of ECG in the workup of acute ischemic stroke. ECG changes are common during acute stroke even in the absence of underlying cardiac pathology. so, clinicians should be aware of these changes while treating the patients. These ECG changes have some prognostic importance

\section{KEYWORDS : ischemic stroke, electrocardiographic changes}

\section{INTRODUCTION:}

Stroke is the leading cause of long-term adult disability and the fifth leading cause of death in the United States, with $\approx 795000$ stroke events in the United States each year ${ }^{1,2}$. Two types of strokes are more common. They are ischemic and hemorrhagic strokes. In these two strokes, ischemic stroke is more common (80\%) than hemorrhagic stroke. Major etiologies for ischemic strokes are cardio embolic, thrombosis of vessels.

Electrocardiographic changes (ECG) are more common in stroke ${ }^{3}$.These ECG changes in the acute state of ischemic stroke resembles myocardial infarction/ischemia. These ECG changes are creating a diagnostic dilemma for clinicians. So, clinicians should aware of these changes while attending the stroke cases.

\section{AIMS AND OBJECTIVES:}

To study the electrocardiographic (ECG) changes in acute ischemic stroke.

\section{MATERIALS AND METHODS:}

Present study was conducted in the department of General medicine, Kamineni Institute of medical sciences, Narketpally. This is a hospital based prospective study, conducted over a period of one year from October 2018 to September 2019. A total of seventy patients admitted with acute ischemic stroke were included in the study. For all patients CT/MRI brain was performed to confirm the diagnosis. Detailed history was taken along with complete neurological and systemic examination. A 12 lead ECG was taken for all patients at the time of admission.

\section{INCLUSION CRITETIRIA:}

- Patients diagnosed with acute ischemic stroke only.

- Patients aged 40 years, and more were included.

\section{EXCLUSION CRITERIA:}

- Patients diagnosed with hemorrhagic stroke.

- Patients aged less than 40 years.

\section{RESULTS:}

Among seventy patients with acute ischemic stroke 44(62.9\%) patients were males and 26(37.1\%) were females. The mean age of the patients was $60.35 \pm 10.21$ years. Out of 70 patients that were included, 64(91.42\%) patients were having ECG changes and 6(8.57\%) patients had normal ECG. Some patients have more than one ECG change.

Teable-1 : Gender Distribution In Patients Of Acute Ischemic Stroke

\begin{tabular}{|l|l|l|}
\hline GENDER & NO. OF PATIENTS & PERCENTAGE \\
\hline Males & 44 & $62.9 \%$ \\
\hline Females & 26 & $37.1 \%$ \\
\hline Total & 70 & $100 \%$ \\
\hline
\end{tabular}

Figure-1. Gender distribution

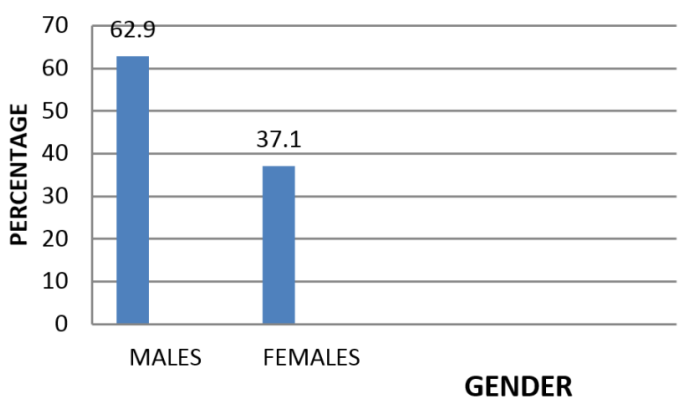

Table-2: Distribution of electrocardiographic (ECG) changes in patients with acute ischemic stroke.

\begin{tabular}{|l|l|l|l|}
\hline ECG changes & $\begin{array}{l}\text { Males } \\
(\mathbf{n}=44)\end{array}$ & $\begin{array}{l}\text { Females } \\
(\mathbf{n}=\mathbf{2 6})\end{array}$ & $\begin{array}{l}\text { Total } \\
(\mathbf{n}=\mathbf{7 0})\end{array}$ \\
\hline Normal ECG & $4(9.09 \%)$ & $2(7.69 \%)$ & $6(8.57 \%)$ \\
\hline Prolonged QTc interval & $8(18.18 \%)$ & $5(19.23 \%)$ & $13(18.57 \%)$ \\
\hline ST segment changes & $11(25 \%)$ & $7(26.92 \%)$ & $18(25.71 \%)$ \\
\hline T wave inversion & $17(38.6 \%)$ & $10(38.46 \%)$ & $27(38.57 \%)$ \\
\hline LVH & $4(9.09 \%)$ & $2(7.69 \%)$ & $6(8.57 \%)$ \\
\hline Tachycardia & $3(6.81 \%)$ & $2(7.69 \%)$ & $5(7.14 \%)$ \\
\hline Bradycardia & $2(4.54 \%)$ & $1(3.84 \%)$ & $3(4.28 \%)$ \\
\hline Atrial fibrillation $(\mathrm{AF})$ & $1(2.27)$ & $1(3.84 \%)$ & $2(2.85 \%)$ \\
\hline
\end{tabular}

The most common ECG change is T wave inversion, present in total of $27(38.57 \%)$ patients and this is present in $17(38.6 \%)$ of male patients and $10(38.46 \%)$ of female patients. 
Figure -2.ECG changes in patients of acute ischemic stroke.

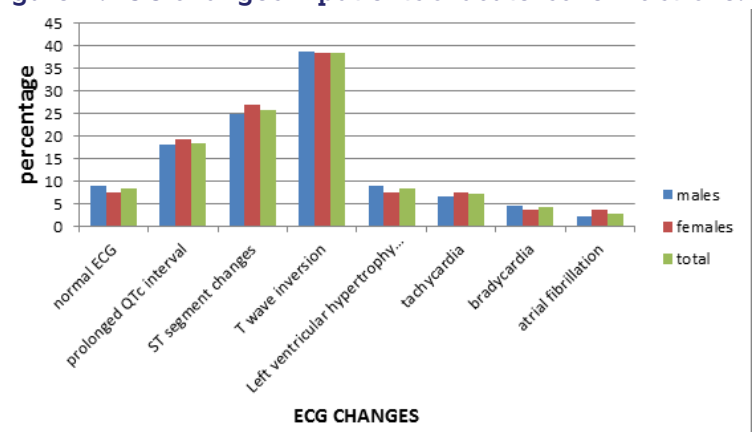

The second most common ECG change is ST segment changes, present in $18(25.71 \%)$ patients. Among these $11(25 \%)$ patients were males and $7(26.92 \%)$ were females.

Other changes like prolonged QTc interval and left ventricular hypertrophy were also present. Prolonged QTc interval is present in $13(18.57 \%)$ patients. In this $8(18.18 \%)$ patients are males and $5(19.23 \%)$ patients are females. $7.14 \%$ of patients have tachycardia, $4.28 \%$ of patients have bradycardia and $2.85 \%$ of patients have atrial fibrillation.

\section{DISCUSSION:}

The ECG changes are frequently appearing in acute ischemic stroke. These changes mimic myocardial ischemia. Clinicians get confused these changes as they mimic acute myocardial ischemia. So, Clinicians be should be aware of these changes while treating the patients of acute ischemic stroke.

In our study, among seventy patients of acute ischemic stroke, $8.57 \%$ of patients had normal ECG and $91.42 \%$ of patients had ECG changes. Goldstein et al $^{4}$, in their study reported that $8 \%$ of cases of CVA had no ECG change and $92 \%$ had ECG changes. Oppenheimer et $\mathrm{al}^{5}$, reported in their study that the new ECG changes in acute ischemic stroke were 15 to $30 \%$.

In our study most common ECG change observed is T wave inversion, which is present in $38.5 \%$ of patients. Togha $\mathrm{M} \mathrm{et}^{6} \mathrm{l}^{6}$, in their study found that the T wave abnormality (39.9\%) was the most common ECG change which is followed by prolonged QTc interval (32.4\%) and arrhythmias (27.1\%).

McDermott et $\mathrm{al}^{7}$, in their study reported that among 51 patients with ischemic stroke or TIA, 15(29\%) patients had ST segment depression and $18(35 \%)$ patients had ventricular arrhythmias. In our study $18(25.71 \%)$ patients have ST segment changes.

There are studies which shows that the electrocardiographic changes that appear during cerebral injury are because of increased sympathetic tone but not because of cardiac origin ${ }^{8}$.

\section{CONCLUSION:}

This study shows the importance of ECG in the workup of acute ischemic stroke patients. As ECG changes are common in stroke patients even in the absence of underlying cardiac disease it is important to know these changes while treating the patients and there is a need of further workup. These changes have some prognostic importance.

\section{REFERENCES:}

1. Roger VL, Go AS, Lloyd-Jones DM, et al.; American Heart Association Statistics Committee and Stroke Statistics Subcommittee. Heart disease and stroke statistics-2011 update: a report from the American Heart Association.Circulation. 2011; 123:e18-e209

2. Mozzafarian D, Benjamin EJ, Go AS, et al, on behalf of the American Heart Association Statistics Committee and Stroke Statistics Subcommittee. Heart disease and stroke statistics-2016 update: a report from the American Heart Association.Circulation. 2016; 133:e38-e360.

3. Khechinashvili G, Asplund K. Electrocardiographic changes in patients with acute stroke: a systematic review. Cerebrovasc Dis. 2002;14(2):67-76

4. Goldstein DS. The electrocardiogram in stroke: relationship to pathophysiological type and comparison with prior tracings. Stroke. 1979; 10(3):253-9

5. Oppenheimer SM. Neurogenic cardiac effects of cerebrovascular disease. Current opinion in neurology. $1994 \mathrm{Feb} 1 ; 7(1): 20-4$

6. Togha M, Sharifpour A, Ashraf H, Moghadam M, Sahraian MA Electrocardiographic abnormalities in acute cerebrovascular events in patients with/without cardiovascular disease. Ann Indian Acad Neurol. 2013;16(1):66-71. 6

7. McDermott MM, Lefevre F, Arron M, Martin GJ, Biller J. ST segment depression detected by continuous electrocardiography in patients with acute ischemic stroke or transient ischemic attack. Stroke. 1994;25(9):1820-4

8. Ebrahim K, Mohamadali A, Majid M, Javad A. Electrocardiograph changes in acute ischemic cerebral stroke. Journal of Applied Research in Clinical and Experimental Therapeutics. 2012 Feb 1;12(1):53 